14.06

\title{
Контроль структуры имплантов и систем доставки лекарственных соединений при помощи метода сканирующей электронной микроскопии с энергодисперсионным анализом
}

\author{
(C) Н.Н. Сударева, ${ }^{1,2}$ Н.Н Сапрыкина, ${ }^{1}$ А.Л. Буянов, ${ }^{1}$ К.А. Колбе, ${ }^{3}$ С.А. Божкова ${ }^{4}$ \\ ${ }^{1}$ Институт высокомолекулярных соединений РАН, \\ 199004 Санкт-Петербург, Россия \\ ${ }^{2}$ Санкт-Петербургский медицинский университет им. Павлова, \\ 197022 Санкт-Петербург, Россия \\ ${ }^{3}$ Санкт-Петербургский политехнический университет Петра Великого, \\ 195251 Санкт-Петербург, Россия \\ ${ }^{4}$ Российский научно-исследовательский институт травматологии и ортопедии им. Р.Р. Вредена, \\ 195427 Санкт-Петербург, Россия \\ e-mail: nnsas@mail.ru
}

Поступило в Редакцию 17 декабря 2019 г.

В окончательной редакции 17 декабря 2019 г.

Принято к публикации 17 февраля 2020 г.

Метод сканирующей электронной микроскопии в комплексе с энергодисперсионным спектрометрическим анализом впервые применен для изучения состава материалов, разрабатываемых для медицинских целей. Сформированы хрящевые импланты на основе гидрогелей полиакриламида бактериальной и растительной целлюлоз, продемонстрирована динамика изменения составов имплантов и приграничной костной зоны сустава, свидетельствующая о зависимости процесса остеоинтеграции от природы целлюлозы. Исследованы системы доставки белков на основе пористых ватеритов $\mathrm{CaCO}_{3}$, одним из вариантов систем доставки служат композитные системы, в которых матрицы $\mathrm{CaCO}_{3}$ ядра покрыты оболочкой из нескольких пар слоев полиэлектролитов. Продемонстрирована возможность определения структур полиэлектролитных оболочек в зависимости от методики их формирования, и определено положение инкапсулированного белка в $\mathrm{CaCO}_{3}$ ядрах.

Ключевые слова: сканирующая электронная микроскопия, энергодисперсионная спектроскопия, импланты, системы доставки, терапевтические белки.

DOI: $10.21883 / J T F .2020 .09 .49690 .410-19$

\section{Введение}

Стандартная область применения энергодисперсионной спектроскопии (ЭДС) - материаловедение в металлургии, геологии, археологии [1-3]. В настоящей работе метод ЭДС использован для изучения объектов, созданных для медицинского использования - имплантов на основе полимерных гидрогелей и систем доставки (СД) лекарственных соединений. Метод ЭДС позволяет определять элементный состав микрочастиц по характеристическому рентгеновскому излучению, возбуждаемому пучком электронов от участков образца, при наблюдении в сканирующем электронном микроскопе (СЭМ) [4].

\section{1. Полимерные импланты}

В настоящее время существует высокая потребность в имплантационном материале для реконструктивновосстановительных операций по замещению дефектов суставных хрящей [5]. В пораженных остеоартрозом суставах хрящи разрушаются, что приводит к тяжелым последствиям. Несмотря на большое количество разрабатываемых подходов, направленных на решение проблемы лечения серьезных суставных патологий, основным методом их лечения до сих пор остается метод полного замещения суставов искусственными. Такой метод часто приводит к развитию воспалительных процессов по причине плохой интеграции материалов эндопротезов с живыми тканями организма [5]. Кроме того, искусственные суставы имеют ограниченный срок работы: не более 10-15 лет, что во многих случаях делает возможность их использования проблематичной.

Значительно менее инвазивным методом лечения суставных патологий может быть замена поврежденных участков хряща гидрогелевыми материалами, которые приближаются по содержанию воды и физическим свойствам к некоторым видам живых тканей. Благодаря этому гидрогели обладают хорошей биосовместимостью и рассматриваются как кандидаты на роль искусственных заменителей хрящей, а также межпозвоночных дисков и сосудов [5-7].

Ранее нами было показано, что разработанные в ИВС РАН особо прочные виды композиционных гидрогелей на основе целлюлозы и полиакриламида (ПААм) обладают не только хорошей биосовместимостью с тка- 
нями организма, но и в отличие от многих аналогов по механическим характеристикам и по характеру вязкоупругого поведения близки к суставным хрящам различного вида и локализации [8-14]. Для них, так же как и для суставных хрящей, уровень значений напряжения, фиксируемых в диапазоне деформаций сжатия $30-50 \%$, достигает $10-20 \mathrm{MPa}$, и они способны устойчиво, т.е. без заметного ухудшения механических характеристик, выдерживать „усталостные“ испытания в режимах многократного циклического сжатия до деформации 50-70\% [8-10,13,14]. Такой высокий уровень механических характеристик позволяет гидрогелевым имплантам функционировать в суставах лабораторных животных в качестве искусственных хрящей длительное время (до 180 суток) как в зонах суставов, которые не подвергаются значительным механическим нагрузкам, так и в,нагрузочных“ областях. При этом наблюдается хорошая интеграция имплантов с хрящевыми и костными тканями $[10,12]$. Такой интеграции способствует процесс формирования гидроксиапатита в виде сферолитов различного размера в пограничной области импланткостная ткань [10], однако распределение органической полимерной и неорганической фаз в объеме имплантов и морфология минерализованной области изучены недостаточно, что требует проведения дополнительных исследований. В настоящей работе с целью более глубокого изучения этих эффектов были использованы методы СЭМ и ЭДС.

\section{2. Системы доставки лекарственных соединений}

Задача систем доставки (СД) - пролонгирование действия и увеличение стабильности инкапсулированных лекарств в условиях организма. Заторможенное высвобождение лекарств обеспечивается пористой структурой СД. Рассмотрим возможности ЭДС для определения включения белков (в том числе и терапевтических) в такие компоненты СД, как пористые ватериты карбоната кальция $\left(\mathrm{CaCO}_{3}\right)$. Поскольку $\mathrm{CaCO}_{3}$ растворяется в кислых средах (например, в среде желудка), использовать их в качестве пероральных СД можно только при условии защиты нерастворимыми в кислой среде полимерами. Один из таких вариантов пероральных СД - пористые $\mathrm{CaCO}_{3}$ ядра, заключенные в многослойную оболочку, сформированную методом полиэлектролитной (ПЭ) сборки, т. е. последовательным нанесением слоев полимеров с избыточными зарядами разных знаков. При использовании СД карбонатное ядро, содержащее белок, либо растворяют [15], либо сохраняют [16-18]. Возможен вариант двухуровневой структуры СД, когда $\mathrm{CaCO}_{3}$ ядра включают в альгинатную гранулу, сформованную методом ионного гелирования [19].

Инкапсулирование белков в $\mathrm{CaCO}_{3}$ ядра проводят двумя способами: при соосаждении в процессе формирования ядер и методом диффузии в готовые ядра. Второй способ позволяет включить в $\mathrm{CaCO}_{3}$ ядра меньшее количество белка, чем первый [20,21].

Обнаружение белка в ядрах возможно косвенным методом - по их функциональной активности, в случае, например, инкапсулирования ферментов [22]. Общее количество инкапсулированного в СД белка чаще всего определяют по разнице введенного в процессе инкапсулирования и не включившегося (освободившегося в ходе промывки СД) белка. Наличие инкапсулированного белка (ферритина) в ПЭ капсулах после растворения ядер, содержавших белок, определяют методом трансмиссионной электронной микроскопии (ферритинбелок, содержащий железо, обладающий высокой электронной плотностью; для белков без тяжелых атомов метод мало пригоден). Показано, что расположение белка внутри ПЭ капсулы без $\mathrm{CaCO}_{3}$ ядра определяется зарядом внутреннего полимерного слоя [23]. Популярный метод конфокальной микроскопии (КФМ), широко используемый при исследовании инкапсулирования белков [24], может детектировать наличие или отсутствие в СД белка, меченного флуоресцентными метками. При помощи КФМ было показано, что белок, включенный в $\mathrm{CaCO}_{3}$ ядра методом диффузии, распределяется около поверхности ядер; белок, включенный соосаждением, внутри [25]. К сожалению, в ряде случаев структура и функции меченых объектов могут отличаться от нативных [26], их флуоресценция зависит от ионного окружения [27]. Следует иметь в виду, что КФМ оптический метод с ограниченным разрешением [28]. Одна из современных моделей LSM 710 с аргоновым лазером и масляной иммерсией имеет разрешение не больше $0.2 \mu \mathrm{m}$. Разрешение СЭМ позволяет наблюдать объекты в нанометровом диапазоне.

В наших предыдущих работах был использован комплекс методов СЭМ и ЭДС для решения некоторых задач, возникающих при формировании и использовании систем доставки медицинского назначения, а именно:

1) оценено качество обработки формируемых систем доставки. Освобождение от внутреннего содержимого спор Lycopodium Clavatum, (оболочки которых использованы в качестве систем пероральной доставки терапевтического белка супероксиддисмутазы - СОД), было подтверждено исчезновением азота - характерного элемента белковых компонентов спор [29];

2) подтвержден механизм трансформации $\mathrm{CaCO}_{3}$ ядер при их нахождении в среде, имитирующей кишечник. Наблюдаемое изменение морфологии $\mathrm{CaCO}_{3}$ ватеритов происходит в ходе реакции ионного обмена с окружающей средой, содержащей соли $\mathrm{HPO}_{4}^{2-}$ превращаясь в рыхлые ядра $\mathrm{CaHPO}_{4}$, что способствует высвобождению инкапсулированного белка. Метод ЭДС обнаружил элементы фосфора в трансформированных структурах [30];

3) ЭДС метод позволяет определить наличие остатков $\mathrm{CaCO}_{3}$ ядер в крови и плазме мышей после перорального введения СД, состоящих из альгинатных гранул с СОД в $\mathrm{CaCO}_{3}$ ядрах [31]; 
$a$
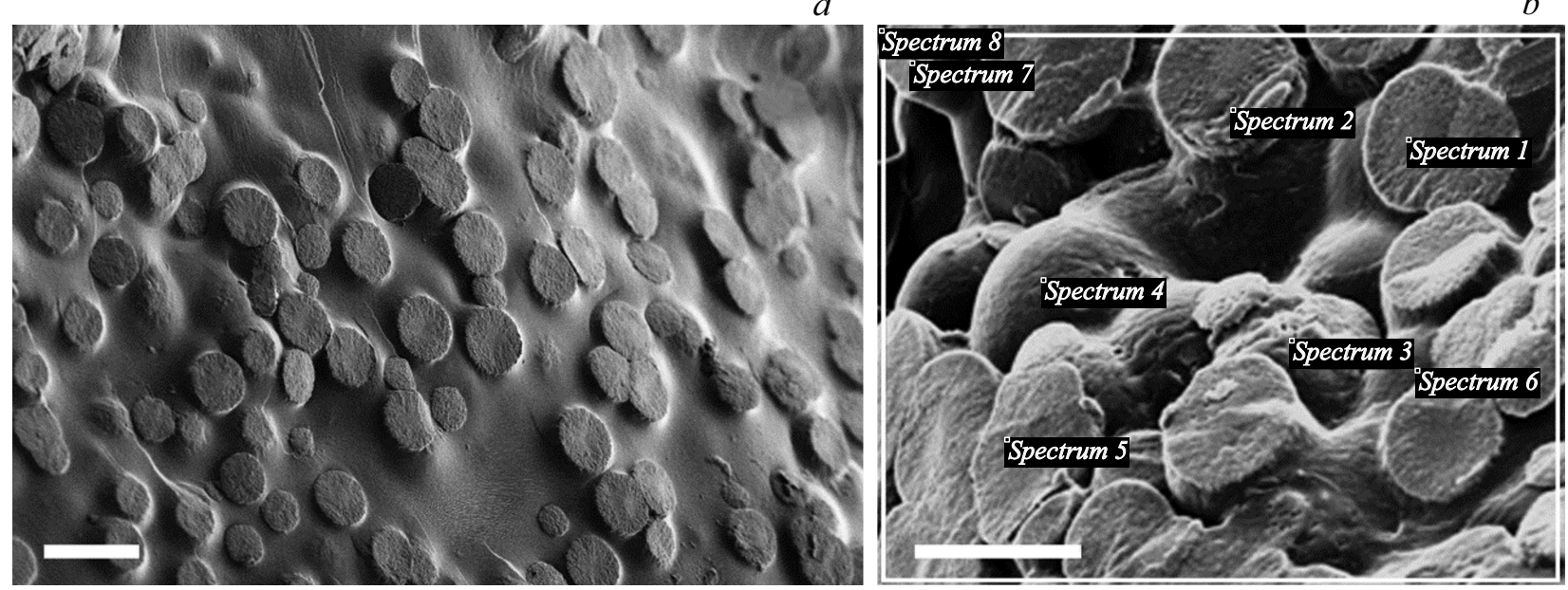

Рис. 1. Микрофотографии сферолитов в гидрогелевом импланте БЦ-ПААм, извлеченном из сустава кролика через 45 суток после операции (субхондральная область). Центральная область импланта $(a)$, область вблизи края имплантата, контактировавшего с костной тканью $(b)$. Маркер - $30 \mu \mathrm{m}$.

Таблица 1. Элементный состав (weight\%) импланта БЦ-ПААм, метод ЭДС

\begin{tabular}{c|c|c|c|c|c|c|c|c|c}
\hline Спектр & $\mathrm{C}$ & $\mathrm{N}$ & $\mathrm{O}$ & $\mathrm{Na}$ & $\mathrm{Mg}$ & $\mathrm{P}$ & $\mathrm{Cl}$ & $\mathrm{Ca}$ & $\mathrm{Ca} / \mathrm{P}$ \\
\hline 1 & 23.56 & 4.22 & 39.92 & 0.51 & 0.30 & 10.72 & 0.28 & 20.48 & 1.91 \\
2 & 29.20 & 4.05 & 38.06 & 0.50 & 0.28 & 9.77 & 0.20 & 17.87 & 1.83 \\
3 & 35.75 & 11.32 & 28.98 & 0.44 & 0.19 & 7.56 & 0.38 & 15.12 & 2.00 \\
5 & 22.35 & 0.00 & 47.90 & 0.57 & 0.32 & 9.77 & 0.25 & 18.75 & 1.92 \\
6 & 18.18 & 0.58 & 46.97 & 0.74 & 0.31 & 10.79 & 0.19 & 22.16 & 2.05 \\
7 & 19.88 & 0.00 & 49.95 & 0.56 & 0.34 & 10.03 & 0.10 & 19.07 & 1.90 \\
8 & 40.95 & 13.63 & 33.55 & 0.35 & 0.13 & 3.66 & 0.24 & 7.36 & 2.01 \\
Среднее & 27.12 & 4.83 & 40.76 & 0.53 & 0.26 & 8.90 & 0.23 & 17.26 & 1.95
\end{tabular}

4) с целью уменьшения размеров ватеритов и увеличения включения в них нейропептидов ядра $\mathrm{CaCO}_{3}$ допировали полианионом декстран сульфатом (DexS). Метод ЭДС показал, что содержание серы на поверхности ядер зависит от способа допирования [31].

В пероральных системах доставки $\mathrm{CaCO}_{3}$ ядра покрыты полимером. Для контроля возможного взаимодействия между загруженным в ядра белком и полимерной оболочкой необходимо владеть информацией о локализации белка в ядрах. Это особенно важно для СД, в которых $\mathrm{CaCO}_{3}$ ядра с белком не удаляют. В литературе информация о распределении белка, инкапсулированного в $\mathrm{CaCO}_{3}$ ядра методом соосаждения, отсутствует. Мы попытались восполнить этот недостаток при помощи методов СЭМ-ЭДС.

\section{3. Результаты и обсуждение}

Исследования структуры имплантов проводили на сколах частично обезвоженных образцов. На сколе гидрогелевого импланта с составом бактериальная целлюлоза-полиакриламид (БЦ-ПААм) видны сферические образования, которые занимают значительную часть объема образца (рис. 1,a). Вблизи наружного края импланта, находившегося в контакте с костью, сферолиты плотно группируются, образуя практически сплошной слой (рис. $1, b)$.

Данные по составу импланта, полученные методом ЭДС, приведены в табл. 1. Высокое содержание кальция (в среднем $17.26 \%$ ) и фосфора (в среднем 8.90\%) прослеживается во всех точках сканирования внутри сферолитов. Средняя величина отношения массовых процентов $\mathrm{Ca} / \mathrm{P}=1.95$ близка к характерному отношению для синтетического гидроксиапатита $\mathrm{Ca}_{5}\left(\mathrm{PO}_{4}\right)_{3} \mathrm{OH}-2.16$. Наличие в пробах углерода и азота указывает на то, что минеральная фаза сферолитов встроена в органическую полимерную фазу, т. е. в полимерную сетку гидрогеля.

В имплантах с составом растительная целлюлозаполиакриламид (РЦ-ПААм) процесс их минерализации протекал иначе: в них гидроксиапатит формировался в основном только в приграничной с костью области с толщиной не более $100 \mu \mathrm{m}$, а в более глубоких слоях импланта содержание минеральной фазы было незначительно (рис. 2,a). Минерализованная область импланта на рисунке расположена слева. На рис. 2, $b$ представлены области сканирования элементного состава импланта в 

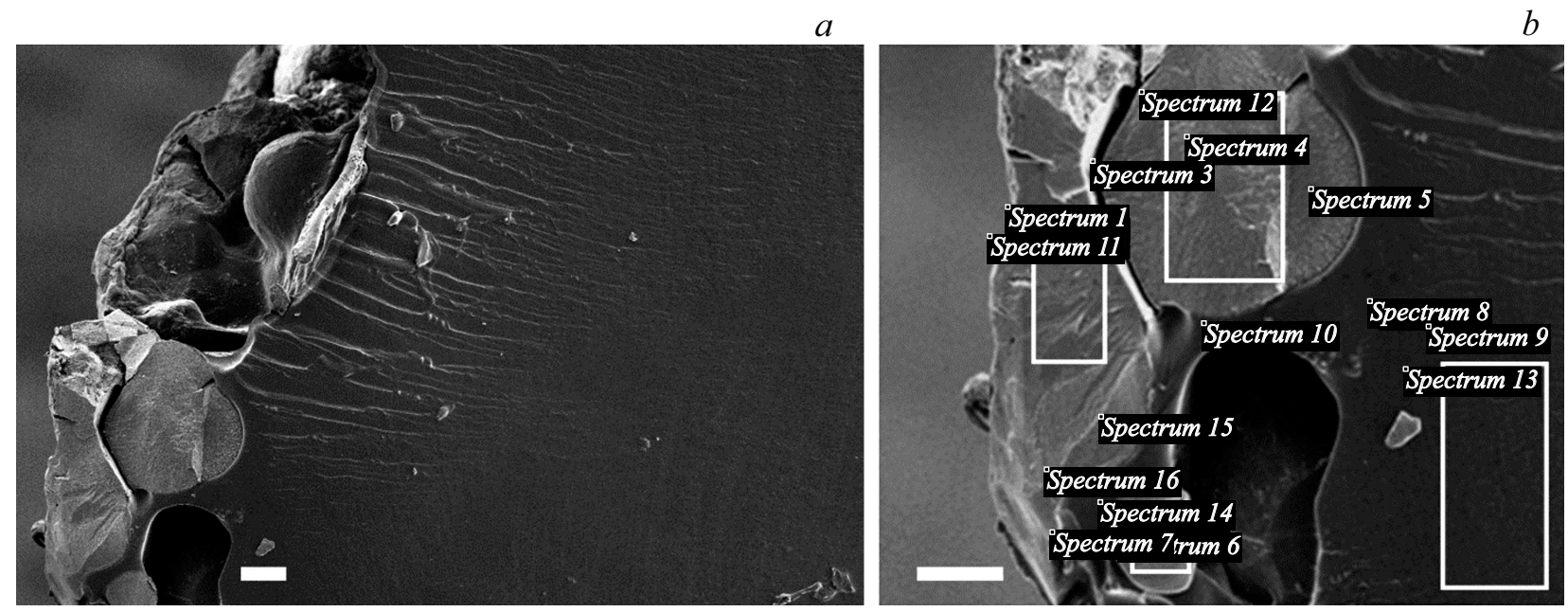

Рис. 2. Микрофотографии сферолитов в гидрогелевом импланте РЦ-ПААм, извлеченном из сустава кролика через 120 суток после операции (субхондральная область). Область импланта вблизи поверхности $(a)$, область сканирования методом ЭДС $(b)$. Маркер - $30 \mu \mathrm{m}$.

Таблица 2. Элементный состав (weight\%) импланта РЦ-ПААм, метод ЭДС

\begin{tabular}{c|c|c|c|c|c|cc|c}
\hline Спектр & $\mathrm{C}$ & $\mathrm{N}$ & $\mathrm{O}$ & $\mathrm{Na}$ & $\mathrm{P}$ & $\mathrm{Ca}$ & $\mathrm{Ca} / \mathrm{P}$ \\
\hline 1 & 16.81 & 1.12 & 43.06 & 0.18 & 12.98 & 25.85 & 1.99 \\
2 & 15.45 & 0.00 & 43.68 & 0.26 & 13.26 & 27.34 & 2.06 \\
3 & 14.66 & 0.00 & 43.17 & 0.19 & 13.93 & 28.05 & 2.01 \\
4 & 18.24 & 1.45 & 39.11 & 0.29 & 13.73 & 27.19 & 1.98 \\
5 & 27.69 & 4.88 & 37.44 & 0.19 & 10.35 & 19.46 & 1.88 \\
6 & 20.25 & 1.32 & 42.46 & 0.20 & 12.05 & 23.72 & 1.97 \\
7 & 49.31 & 22.92 & 25.86 & 0.00 & 0.57 & 1.34 & 2.35 \\
8 & 62.45 & 16.20 & 20.97 & 0.00 & 0.00 & 0.38 & - \\
9 & 60.02 & 15.86 & 23.85 & 0.05 & 0.00 & 0.21 & - \\
10 & 63.36 & 16.04 & 20.12 & 0.00 & 0.00 & 0.48 & - \\
11 & 17.75 & 1.93 & 46.05 & 0.29 & 11.09 & 22.89 & 2.06 \\
12 & 18.02 & 3.69 & 44.25 & 0.30 & 10.88 & 22.86 & 2.10 \\
13 & 51.56 & 19.31 & 29.06 & 0.00 & 0.00 & 0.07 & - \\
14 & 20.42 & 4.61 & 44.44 & 0.24 & 10.16 & 20.13 & 1.98 \\
15 & 18.78 & 0.00 & 45.50 & 0.29 & 11.83 & 23.59 & 1.99 \\
16 & 18.56 & 1.62 & 46.44 & 0.13 & 11.22 & 22.03 & 1.96 \\
Среднее & 30.83 & 6.93 & 37.22 & 0.16 & 8.25 & 16.60 & 2.03
\end{tabular}

приграничной области. Данные по составу гидрогелевого импланта с растительной целлюлозой приведены в табл. 2.

Данные из табл. 2 показывают, что по химическому составу импланта его наружная минерализованная область так же, как и для импланта с составом БЦ-ПААм, насыщена фосфатом кальция: суммарное содержание последнего достигает 40 weight $\%$, причем отношение $\mathrm{Ca} / \mathrm{P}$ и в этом случае близко к двум, что характерно для гидроксиапатита. В областях сканирования зоны гидрогеля (№ 8-10 и 13) содержание Са и Р незначительно, но в них наблюдается высокое содержание $\mathrm{N}$, которое близко к таковому для полиакриламида [10]. Эти данные показывают, что, действительно, в более глубоких слоях импланта с составом РЦ-ПААм минеральная фаза практически отсутствует.

Прежде чем использовать ЭДС анализ для определения количества и расположения элементов внутри исследуемой структуры - в пористых карбонатных ядрах с белками, необходимо „прокалибровать“ систему, т.е. определить погрешность в определении содержания элементов. Усредненные результаты приведены в табл. 3. Средняя погрешность метода составляет около $10 \%$. Здесь же приведены результаты расчета элементного состава белков, основанные на их аминокислотном составе. Наблюдаем удовлетворительную корреляцию расчетных и измеренных данных. При оценке результатов нужно принимать во внимание неоднородность мате- 
Таблица 3. Элементный состав модельных и терапевтических белков

\begin{tabular}{|c|c|c|c|c|c|c|c|c|}
\hline \multirow{2}{*}{ Белок } & \multicolumn{8}{|c|}{ Элементный состав (weight\%)* } \\
\hline & & $\mathrm{C}$ & $\mathrm{N}$ & $\mathrm{O}$ & $\mathrm{S}$ & $\mathrm{Cu}$ & $\mathrm{Zn}$ & $\mathrm{Na}$ \\
\hline \multirow{2}{*}{ Бычий сывороточный альбумин } & Расчет & 56.5 & 18.8 & 22.8 & 2.0 & - & - & - \\
\hline & ЭДС & 54.8 & 20.8 & 20.7 & 2.0 & - & - & 0.5 \\
\hline \multirow{2}{*}{ Лактальбумин } & Расчет & 48.0 & 19 & 32.9 & 0.1 & - & - & - \\
\hline & ЭДС & 38.0 & 27 & 34.8 & 0.2 & - & - & - \\
\hline \multirow{2}{*}{ Лизоцим } & Расчет & 49.0 & 16.3 & 33.0 & 1.9 & - & - & - \\
\hline & ЭДС & 44.0 & 28.0 & 26.6 & 0.4 & - & - & - \\
\hline \multirow{2}{*}{ Миоглобин } & Расчет & 59.6 & 19.0 & 21.0 & 0.4 & - & - & - \\
\hline & ЭДС & 69.0 & 12.7 & 18.0 & 0.25 & - & - & - \\
\hline ИЛ1-ар & ЭДС & 57.20 & 24.15 & 17.24 & 1.21 & - & - & - \\
\hline СОД & ЭДС & 79.31 & 16.43 & 4.16 & 0.03 & 0.03 & 0.02 & - \\
\hline
\end{tabular}

Примечание. * - стандартное отклонение в определении элементного состава составляет $10 \%$.

Таблица 4. Содержание в $\mathrm{CaCO}_{3}$ ядрах элементов, характерных для белков

\begin{tabular}{|c|c|c|c|c|c|c|}
\hline \multirow{3}{*}{ Белок } & \multicolumn{6}{|c|}{ Элементный состав (weight\%) ${ }^{* *}$} \\
\hline & \multicolumn{3}{|c|}{ Поверхность } & \multicolumn{3}{|c|}{ Скол } \\
\hline & $\mathrm{N}$ & $\mathrm{C}$ & $\mathrm{Fe}$ & $\mathrm{N}$ & $\mathrm{C}$ & $\mathrm{Fe}$ \\
\hline Лизоцим & 29 & 0.30 & - & 0 & 0 & - \\
\hline Лактальбумин/ДНС = 1/0.8 & 30 & 0.23 & - & 22 & 0.20 & - \\
\hline Ингибитор трипсина & 30 & 0.20 & - & 21 & 0.10 & - \\
\hline Гемоглобин & 28 & 0.38 & 0.15 & 15 & 0.31 & 0 \\
\hline Миоглобин & 29 & 0.12 & 0 & 18 & 0 & 0 \\
\hline
\end{tabular}

Примечание. ** - стандартное отклонение в определении элементного состава составляет $10 \%$.

риала. Большинство использованных в работе белков произведено фирмой Sigma Aldrich, чистота некоторых (например, миоглобина и лактальбумина) составляет более 90 и $85 \%$ соответственно. Следовые количества $\mathrm{Na}$ отражают особенности процесса выделения и очистки белков.

В настоящей работе методом ЭДС определены элементные составы терапевтических белков: цитокина -антагониста рецептора интерлейкина 1 (ИЛ1-ар) и антиоксидантного фермента - супероксиддисмутазы (СОД) с неизвестным аминокислотным составом (табл. 3, две нижние строки). Молекула СОД - димер, каждый мономер которого содержит один атом $\mathrm{Cu}$ или $\mathrm{Zn}$. Заметим, что этот белок в инкапсулированном виде проявлял пролонгированное действие в организмах крыс при пероральном введении [29].

Для определения расположения белков внутри $\mathrm{CaCO}_{3}$ ядер, куда они были введены методом соосаждения, проводили определение элементного состава поверхно- стей целых ядер и поверхностей сколов. Результаты измерений состава методом ЭДС в сравнении с расчетными данными приведены в табл. 4. Характеристическим элементом, позволяющим определять наличие белка в $\mathrm{CaCO}_{3}$ ядрах, служит азот.

Сера также содержится во многих белках. К сожалению, в детектируемых количествах ее можно обнаружить не во всех использованных белках, например, в лактальбумине ее не больше $0.2 \%$. Поэтому для повышения чувствительности анализа ЭДС мы присоединили к лактальбумину флуоресцентную метку данзилхлорид, содержащую в своем составе азот $(\mathrm{N})$ и серу $(\mathrm{S})$.

На основании данных, приведенных в табл. 4, можно сделать вывод о том, что белки, включенные в ядра, распределены по всему ядру. Большая концентрация элементов, содержащихся в белках, наблюдается преимущественно на поверхности ядра. Это можно объяснить процедурой тщательной отмывки инкапсулированных 
$a$
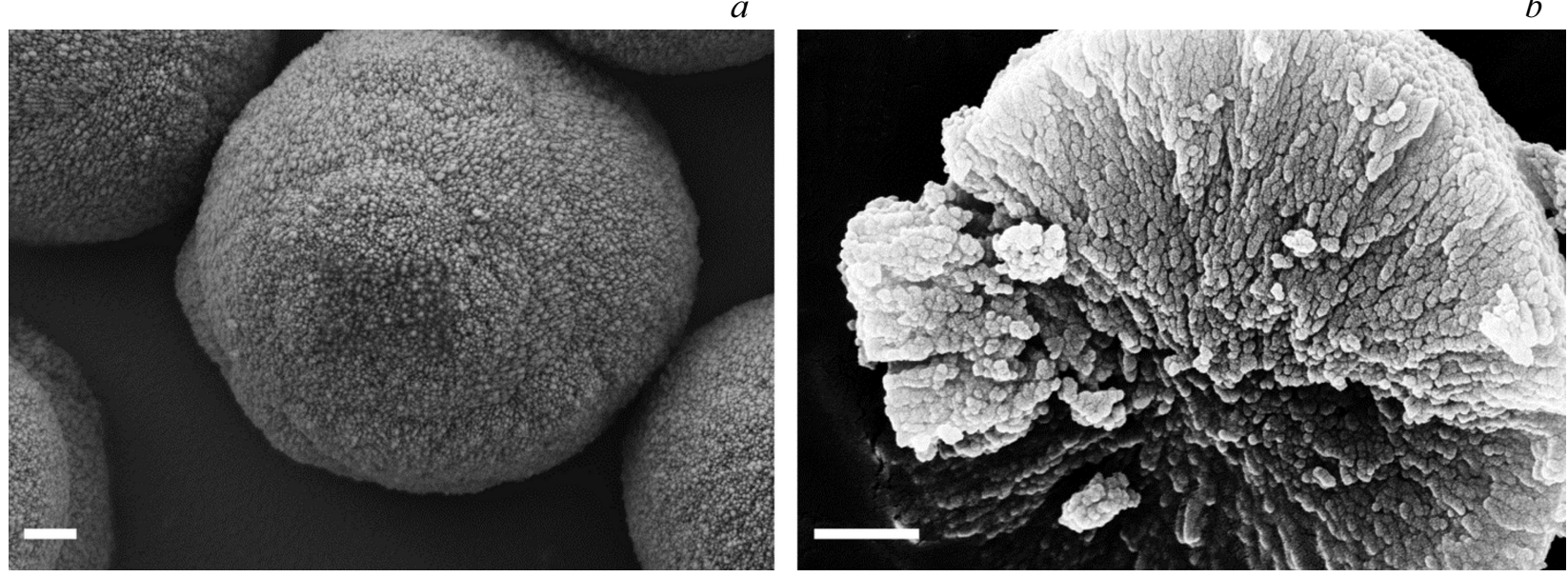

$c$
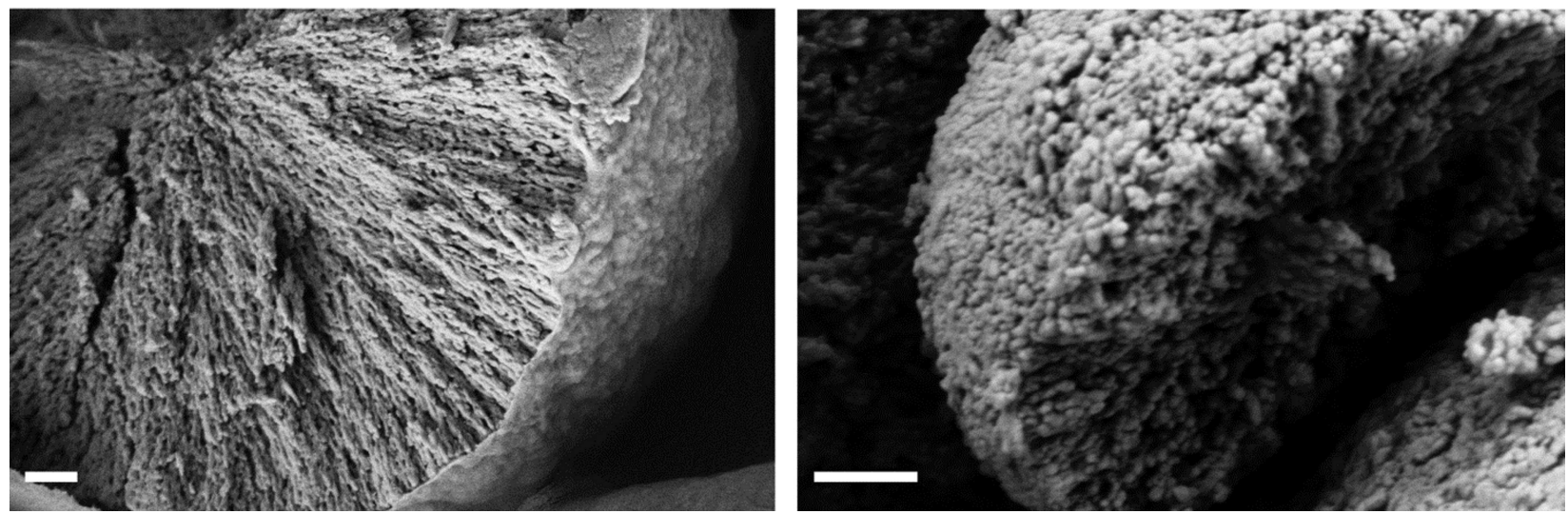

Рис. 3. Микрофотографии $\mathrm{CaCO}_{3}$ ядер $(a)$, сколы: $\mathrm{CaCO}_{3}$ ядер $(b)$, ядер с плотной ПЭ оболочкой $(c)$ и с ПЭ оболочкой, проникающей в поры $(d)$. Маркер - $200 \mathrm{~nm}$.

ядер (см. разд. 4), в процессе которой не исключено диффузионное движение белков из ядер.

Еще один вариант использования метода ЭДС для характеристик полученных СД - выявление особенностей нанесения слоев полиэлектролитов при формировании послойной оболочки на $\mathrm{CaCO}_{3}$ матрицах.

Морфология ПЭ оболочек, визуализованная при помощи СЭМ (рис. 3) коррелирует с ЭДС характеристиками поверхности $\mathrm{CaCO}_{3}$ ядер, покрытых ПЭ оболочками разного состава и без них. На поверхности $\mathrm{CaCO}_{3}$ ядер (рис. 3, $\left.a, b\right)$ нет атомов азота. ПЭ оболочки формировали из 5 пар слоев полианиона альгината (А) и полиамфолита желатина А (Ж), величина изоточки последнего близка к 8.0, следовательно, в нейтральной среде он проявляет свойства поликатиона. В работе [32] проведены реологические исследования смесей указанных ПЭ с разным составом компонентов. Увеличение вязкости смеси альгинат-желатин при определенном составе $(\mathrm{A} / Ж=1 / 3)$ свидетельствует о наличии комплексообразования ПЭ, выражающегося в формировании плотной оболочки (рис. 3,c). Ослабление взаимодействия в смеси состава $(\mathrm{A} / Ж=3 / 1)$ позволяет полимерам проникать в поры $\mathrm{CaCO}_{3}$ ядра. В первом слу- чае на поверхности СД присутствуют 5.8\% атомов азота (в молекулах желатина их 18\%). На поверхности ядер, покрытых ПЭ с другим соотношением ПЭ $(\mathrm{A} / Ж=3 / 1)$ азот практически не определяется, что подтверждено методом ЭДС. СЭМ метод показывает наличие в этом случае лишь тонкого конформного покрытия отдельных кристаллитов ядер $\mathrm{CaCO}_{3}$ (рис. 3,d).

\section{4. Материалы и методы}

Композиционные гидрогели синтезировали методом радикальной сополимеризации акриламида с низкомолекулярным сшивающим агентом (N,N' - метиленбис-акриламид), которую проводили внутри набухших в реакционном растворе целлюлозных матриц. Начальные концентрации акриламида, МБА и инициатора (ацетат кобальта III) в водном реакционном растворе были равны $7.4,1.4 \cdot 10^{-3}$ и $0.5 \cdot 10^{-3} \mathrm{~mol} / 1$ соответственно. Конверсия мономера, близкая к $100 \%$, достигалась за $2 \mathrm{~h}$ проведения процесса при $25^{\circ} \mathrm{C}$. Затем гидрогели многократно промывали в дистиллированной воде для удаления низкомолекулярных примесей. Одновременно 
происходило набухание гелей до равновесного состояния.

Бактериальную целлюлозу (БЦ) выращивали с использованием штамма ВКМ-880 в водном растворе, содержащем 2 weight $\%$ глюкозы, 0.3 weight $\%$ дрожжевого экстракта и 2 vol.\% этанола при $30^{\circ} \mathrm{C}$ в течение 14 days в цилиндрических стеклянных сосудах. Выращенные гельпленки БЦ имели толщину около 20-25 mm и содержали около 99 weight $\%$ воды. Далее их отмывали в водном растворе щелочи (2 weight $\% \mathrm{NaOH}$ ) при температуре, близкой к $100^{\circ} \mathrm{C}$, для удаления бактерий Acetobacter xylinum, а затем - в дистиллированной воде [8].

Матрицы из растительной целлюлозы (РЦ) были получены растворением целлюлозы растительного происхождения (хлопковый линтер) в трифторуксусной кислоте с последующей отливкой раствора на стекло [9]. Гидрогели получали в виде пластин с толщиной 3.5-4.5 mm, из которых далее вырезали цилиндры с диаметром 3-5 mm. Образцы гидрогелей имплантировали в сформированные глубокие дефекты хряща коленного сустава кроликов породы Шиншилла. Техника имплантации опубликована ранее [12].

Все соли, использованные для синтеза $\mathrm{CaCO}_{3}$ ядер, были произведены Sigma-Aldrich (St. Louis, США). Инкапсулировали в $\mathrm{CaCO}_{3}$ ядра следующие белки: гемоглобин, бычий сывороточный альбумин, ингибитор трипсина, лизоцим, миоглобин и $\beta$-лактальбумин (все производства Sigma-Aldrich). Терапевтические белки супероксиддисмутаза (СОД) и антагонист рецептора интелейкина 1 (ИЛ1-ар) получены из НИИ Высокочистых биопрепаратов (СПб, Россия). Для формирования ПЭ оболочки использовали биосовместимые и биоразлагаемые полимеры: полианион-альгинат $\mathrm{Na}$ (низковязкий медицинского назначения производства Архангельского водорослевого комбината, Россия), $\mathrm{MM}=300 \mathrm{kDa}$ и полиамфолит-желатин кислотной обработки (тип А, Франция), $\mathrm{MM}=355 \mathrm{kDa}$. Так как величина изоточки последнего близка к 8, в нейтральных условиях сборки он является поликатионом.

Синтез $\mathrm{CaCO}_{3}$ ядер, инкапсулирование белков и формирование на ядрах полиэлектролитных оболочек проводили согласно модифицированной методике [19]. Пористые ватериты $\mathrm{CaCO}_{3}$ получали в процессе coocaждения $1 \mathrm{M}$ растворов $\mathrm{Na}_{2} \mathrm{CO}_{3}$ и $\mathrm{CaCl}_{2} \times 2 \mathrm{H}_{2} \mathrm{O}$ при $30 \mathrm{~s}$ перемешивании. После $15 \mathrm{~min}$ стояния суспензии осадок трижды промывали дистиллированной водой, затем водно-ацетоновой смесью с увеличивающейся до $100 \%$ концентрацией ацетона. Сушили при $T=50^{\circ} \mathrm{C}$ до постоянного веса. Инкапсулирование белков осуществляли методом соосаждения. Белок в концентрации $2 \mathrm{mg} / \mathrm{ml}$ добавляли в раствор одной из солей, далее процедуру проводили согласно описанному выше протоколу.

ПЭ оболочки формировали следующим образом: $\mathrm{CaCO}_{3}$ ядра помещали сначала в раствор альгината, перемешивали в течение $10 \mathrm{~min}$ на программируемом ротаторе-миксере MultiBio RS-24 (BioSan, Латвия), центрифугировали, супернатант сливали, заменяя его ди- стиллированной водой. Промывку повторяли трижды. Затем осадок заливали раствором желатина А, помещали на $1 \min$ в ультразвуковую ванну при частоте $35 \mathrm{kHz}$ (Fritsch GMBH, Idar-Oberstein, Германия). Процесс нанесения пары ПЭ повторяли 5 раз. Окончательный осадок сушили, как и $\mathrm{CaCO}_{3}$ ядра. Проведены два типа экспериментов с соотношением концентраций полиэлектролитов $1 / 3$ и $3 / 1$; концентрация первого слоя альгината была $1 \mathrm{mg} / \mathrm{ml}$ или $3 \mathrm{mg} / \mathrm{ml}$ в разных случаях соответственно варьировали и концентрацию желатина А.

Морфологию $\mathrm{CaCO}_{3}$ ядер, наличие полимерной оболочки на них и фактуру ее поверхности визуализировали с помощью СЭМ. Для получения СЭМ микрофотографий всех исследованных в работе объектов использовали сканирующий электронный микроскоп Supra 55VP (Carl Zeiss, Германия). Исследуемые объекты помещали на предметный столик с токопроводящим скотчем и для обеспечения электропроводности поверхности образцов, исключения помех за счет накопления поверхностного заряда при сканировании, а также для повышения контрастности, покрывали платиной методом катодного распыления на установке Quorum 150 (Oxford Instruments, Великобритания). Толщина покрытия порядка $10 \mathrm{~nm}$. Для определения элементного состава имплантов, а также внутреннего содержимого карбонатных ядер с инкапсулированными белками объекты исследования погружали в жидкий азот и получали сколы образцов. Данные об элементном составе участков скола или поверхности образцов получали при помощи системы микроанализа INCA Energy с детектором X-Max 80 фирмы Oxford Instruments, комплектуемой с микроскопом SUPRA 55VP. Оценку надежности результатов на примере лиофилизатов белков проводили следующим образом. Получали микрофотографии гомогенного порошка. На отдельных участках поверхности, а также на всей площади определяли элементный состав объекта. Данные усредняли по разным участкам поверхности (3-5), а также по всей поверхности (2-3). Стандартное отклонение составляло не более $10 \%$.

\section{Заключение}

Совокупность приведенных данных показала, что методы СЭМ и ЭДС, используемые совместно, предоставляют ценную информацию о химическом составе имплантов в различных их областях, а также о распределении минеральной фазы в объеме имплантов и в целом об их морфологии. Кроме того, благодаря указанным методам получена возможность определения локализации белков, инкапсулированных в карбонатных ядрах, и контроля структуры полиэлектролитной оболочки в системах доставки терапевтических объектов. Работа продемонстрировала эффективность применения комплекса методов СЭМ-ЭДС для биомедицинских исследований. 


\section{Благодарности}

Авторы выражают благодарность А.А. Ткаченко и А.К. Хрипунову за предоставление образцов бактериальной целлюлозы.

\section{Соблюдение этических стандартов}

Содержание и использование лабораторных животных соответствовало правилам ФГБУ „РНИИТО им. Р. Р. Вредена“ и рекомендациям Национального совета по исследованиям и национальным законам.

\section{Конфликт интересов}

Авторы заявляют, что у них нет конфликта интересов.

\section{Список литературы}

[1] Митин Д.И., Глебов В.В., Шурыгин А.Ю. // Приволжский научный вестник. 2013. № 12. С. 41-42.

[2] Медведев А.А., Посеренин А.И. // Горный информационноаналитический бюллетень. 2016. № 11. С. 115-124.

[3] Лобода А.Ю., Терещенко Е.Ю., Антипенко А.В., Ретивов В.М., Пресняков М.Ю., Колобылина Н.Н., Кондратьев О.А., Шишлина Н.И., Яцишина Е.Б, Кашкаров П.К. // Приволжская археология. 2018. № 4. C. 203-221. DOI: 10.24852/2018/4.26.203.221

[4] Goldstein J., Newbury D.E., Joy D.C., Lyman C.E., Echlin P., Lifshin E., Sawyer L., Michael J.R. Scanning Electron Microscopy and X-Ray Microanalysis: N Y.: Springer Science \& Business Media, 2012. 689 p.

[5] Ku D.N. In: Fred A., Filipe J., Gamboa H., eds, Biomedical Engineering Systems and Technologies, BIOSTEC 2008. Communications in Computer and Information Science, Vol. 25. Springer, Berlin, Heidelberg, 2008. P. 85-95. DOI: 10.1007/978-3-540-92219-3_6

[6] Sciaretta F.V. // Eur. Rev. Med. Pharmacol. Sci. 2013. Vol. 17. N 22. P. 3031-3038.

[7] Nandgaonkar A.G., Krause W.E., Lucia L.A. In: H. Liu (Ed.), Nanocomposites for Musculoskeletal Tissue Regeneration, Woodhead Publishing, Elsevier, Amsterdam, 2016. P. 187-212. DOI: $10.1016 / \mathrm{B} 978-1-78242-452-9.00009-1$

[8] Buyanov A.L., Gofman I.V., Revel'skaya L.G., Khripunov A.K., Tkachenko A.A. // J. Mech. Behav. Biomed. Mater. 2010. Vol. 3. P. 102-111. DOI: 10.1016/j.jmbbm.2009.06.001

[9] Буянов А.Л., Гофман И.В., Хрипунов А.К., Ткаченко А.А., Ушакова Е.Э. // Высокомолек. соед. Сер. А. 2013. T. 55. Вып. 5. С. 512-522. [Buyanov A.L., Gofman I.V., Khripunov A.K., Tkachenko A.A., Ushakova E.E. // Polym. Sci. 2013. Vol. A. 55. N 5. P. 302-312. DOI: $10.1134 / \mathrm{S} 0965545 \mathrm{X} 13050027]$

[10] Буянов А.Л., Гофмиан И.В., Божккова С.А., Сапрыкина Н.Н., Кочиш А.Ю., Нетылько Г.И., Хрипунов А.К., Смыслов Р.Ю., Афбанасьев А.В., Панарин Е.Ф. // ЖПХ. 2016. Т. 89. Вып. 5. С. 639-646. [Buyanov A.L., Gofman I.V., Bozhkova S.A., Saprykina N.N., Kochish A.Yu., Netyl;ko G.I., Khripunov A.K., Smyslov R.Yu., Afanas'ev A.V., Panarin E.F. // Russ. J. Appl. Chem. 2016. Vol. 89. P. 772-779. DOI: $10.1134 /$ S1070427216050141]
[11] Velichko E.V., Buyanov A.L., Saprykina N.N., Chetverikov Yu.O., Duif C.P., Bouwman W.G., Smyslov R.Yu. // Eur. Polym. J. 2017. Vol. 88. P. 269-279. DOI: $10.1016 /$ j.eurpolymj.2017.01.034

[12] Божккова С.А., Буянов А.Л., Кочиш А.Ю., Румакин В.П., Хрипунов А.К., Нетылько Г.И., Смыслов Р.Ю., Абанасьев А.В., Панарин Е.Ф. // Морфология. 2016. Т. 149. Вып. 2. С. 8-53.

[13] Gofman I.V., Buyanov A.L., Bozhkova S.A., Netylko G.I. Mechanical properties of new hydrogel implants substituent of joint cartilage: in-vivo tests. 1st International Symposium on Mechanics, Aberdeen, Scotland, UK; 9-12 July 2018, Abstracts. https://mechanics.nscj.co.uk/sessions/daVinci.html

[14] Buyanov A.L., Gofman I.V., Saprykina N.N. // J. Mech. Behav. Biomed. Mater. 2019. Vol. 100. https://doi.org/10.1016/j.jmbbm.2019.103385

[15] Volodkin D.V., Petrov A.I., Prevot M., Sukhorukov G.V. // Langmuir: ACS J. Surf. Colloid. 2004. Vol. 20. N 8. P. 3398-3406. DOI: $10.1021 / 1 \mathrm{a} 036177 \mathrm{z}$

[16] Liu D., Jiang G., Yu W., Li L., Tong Z., Kong X., Yao J. // Mater. Lett. 2017. Vol. 188. P. 263-266. DOI:10.1016/j.matlet.2016.10.117

[17] Peng C., Zhao Q., Gao C // Colloid. Surf. A: Physicochem. Eng. Aspects. 2010. Vol. 353. P 132-139. DOI: 10.1016/j.colsurfa.2009.11.004

[18] Kudryavtseva V.L., Zhao L., Tverdokhlebov S.I., Sukhorukov G.B. // Colloid. Surf. B: Biointerface. 2017. Vol. 15. P. 481-489. DOI: 10.1016/j.colsurfb.2017.06.011

[19] Sudareva N., Suvorova O., Saprykina N., Vilesov A., Belityukov P., Petunov S. // J. Microencapsul. 2016. Vol. 33. N 5. P. 487-496. DOI: $10.1080 / 02652048.2016 .1206146$

[20] Volodkin D.V., Larionova N.I., Sukhorukov G.B // Biomacromolecules. 2004. Vol. 5. N 5. P. 1962-1972. DOI: $10.1021 / \mathrm{bm} 049669 \mathrm{e}$

[21] Sudareva N., Popova H., Saprykina N., Bronnikov S. J. // Microencapsul. 2014. Vol. 31. N 4. P. 333-343. DOI: $10.3109 / 02652048.2013 .858788$

[22] Бородина Т.Н., Румш Л.Д., Кунижев С.М., Сухоруков Г.Б., Ворожиов Г.Н., Фельдман Б.М., Марквичева Е.А. // Биомед. химия. 2007. Т. 53. Вып. 5. С. 557-565.

[23] Казакова Л.И., Дубровский А.В., Санталова И.М., Мошков Д.А., Аполонник Н.В., Шабарчин Л.И. // Биоорг. химия. 2012. Т. 38. Вып. 1. С. 64-69. [Kazakova L.I., Dubrovskyi A.V., Santalova I.M., Moshkov D.A., Apolonnik N.V., Shabarchina L.I. // Russ. J. Bioorg. Chem. 2012. Vol. 38. N 1. P. 51-55. DOI: $10.1134 / \mathrm{S} 1068162012010128]$

[24] She Z., Wang C.X., Li J., Sukhorukov G.B., Antipina M.N. // Biomacromolecules. 2012. Vol. 13. N 7. P. 2174-2180. DOI: $10.1021 / \mathrm{bm} 901450 \mathrm{r}$

[25] Petrov A.I., Volodkin D.V., Sukhorukov G.B. // Biotechnol. Progress. 2005. Vol. 21. N 3. P. 918-925. DOI: $10.1021 / \mathrm{bp} 0495825$

[26] Сударева Н.Н., Суворова О.М., Паутов В.Д. // Вестник ТГУ: Сер. химия. 2019. Вып. 1. С. 147-163.

[27] Лакович Д. Основы флуоресцентной спектроскопии. М.: Мир, 1986. 496 с.

[28] Штейн Г.И. Руководство по конфокальной микроскопии. СПб.: Изд-во Политех. ун-та, 2007. 78 с. 
[29] Sudareva N., Suvorova O., Saprykina N., Vilesov A., Bel'tyukov P., Petunov S., Radilov A. // J. Mat. Chem. B. 2017. Vol. 5. N 37. P. 7711-7720. DOI: $10.1039 / \mathrm{C} 7 \mathrm{~TB} 01681 \mathrm{~F}$

[30] Sudareva N.N., Saprykin N.N., Popova E.V., Vilesov A.D. In: Cohen A, ed. Calcium Carbonate: Occurrence, Characterization and Applications. N Y.: Nova Sci Publishers, Inc (NOVA). 2015. P. 73-95.

[31] Sudareva N., Suvorova O., Saprykina N., Smirnova N., Bel'tyukov P., Petunov S., Radilov A., Vilesov A. // J. Microencapsul. 2018. Vol. 35. N 7-8. P. 619-634. DOI: $10.1080 / 02652048.2018 .1559247$

[32] Колбе К.А., Сударева Н.Н., Елоховский В.Ю., Сапрыкина Н.Н. Тезисы докладов Третьей Междунар. конф. „Физика - наукам о жизни“, 14-18 октября 2019. ФТИ РАН, СПб. С. 163. 